10

\title{
Влияние рентгеновского и УФ лазерного облучения на оптические свойства щелочносодержащих силикатных стекол
}

\author{
(ㄱ А.И. Сидоров, А.И. Игнатьев, В.Д. Дубровин, Н.В. Никоноров \\ Университет ИТМО, \\ 197101 Санкт-Петербург, Россия \\ e-mail: sidorov@oi.ifmo.ru
}

Поступила в редакцию 28.02.2019 г.

В окончательной редакции 28.02.2019 г.

Принята к публикации 23.04.2019 г.

\begin{abstract}
Представлены результаты комплексного воздействия рентгеновского и ультрафиолетового (УФ) наносекундного лазерного излучения на щелочносодержащие силикатные стекла. Показано, что под действием рентгеновского излучения в стеклах возникают центры окраски, обладающие люминесцентными свойствами, что связано с увеличением концентрации структурных дефектов сетки стекла. Под действием лазерного излучения происходит разрушение этих дефектов, что сопровождается обесцвечиванием стекла и исчезновением люминесценции в облученных зонах. Исследованы динамика обесцвечивания стекла под действием лазерного излучения и влияние ионов щелочных металлов ( $\mathrm{Li}, \mathrm{Na}, \mathrm{K})$ на данный процесс. Предложены механизмы разрушения центров окраски лазерным излучением.
\end{abstract}

Ключевые слова: силикатное стекло, поглощение, люминесценция, рентгеновское излучение, лазерное излучение, центры окраски.

DOI: $10.21883 / O S .2019 .09 .48202 .92-19$

\section{Введение}

Известно, что воздействие ионизирующих излучений (рентгеновского, гамма, электронного, УФ и др.) способно изменять оптические свойства стекол [1-10]. Как правило, после такого облучения многокомпонентные исходно бесцветные стекла приобретают окраску в видимой области спектра за счет возникновения наведенных центров окраски дефектов сетки стекла. Данный эффект используется, в частности, в дозиметрах ионизирующих излучений [11]. Многие типы дефектов, возникающих под действием ионизирующих излучений, обладают не только полосами поглощения, но и полосами люминесценции в видимой области спектра [12-14]. Следует отметить, что дефекты, наведенные ионизирующими излучениями, являются нестабильными и полностью исчезают при термообработке стекла [15].

Стекла как оптические материалы являются удобными объектами для записи оптической информации. Поэтому формирование в стеклах центров окраски и люминесцентных центров под действием ионизирующих излучений привлекает внимание исследователей не только с научной, но и с прикладной точек зрения. Так, в работе [16] были проведены исследования формирования люминесцентных центров при облучении рентгеновским и УФ излучениями в натриево-боратном стекле, активированном ионами $\mathrm{Eu}^{2+}, \mathrm{Ce}^{3+}$ и $\mathrm{Sm}^{3+}$, применительно к использованию в устройствах оптической памяти. В работе [17] было показано, что для создания оптической памяти могут быть использованы вольфраматфосфатные стекла с центрами окраски, созданными УФ лазерным излучением.
В ряде работ продемонстрирована возможность записи оптической информации в стеклах путем создания или трансформации некоторых ансамблей, имеющих отличную от матрицы стекла люминесценцию. Такими ансамблями могут являться нейтральные или заряженные молекулярные кластеры серебра, которые обладают интенсивной люминесценцией в видимой области спектра [18-20]. Так, в работе [18] была показана возможность записи оптической информации в серебросодержащих фототерморефрактивных стеклах путем создания люминесцентных центров УФ излучением. В работе [19] продемонстрирована возможность записи и стирания оптической информации воздействием наносекундного УФ лазерного излучения. В работе [20] была произведена запись информации путем формирования в цинкфосфатном серебросодержащем стекле люминесцентных молекулярных кластеров серебра фемтосекундным лазерным излучением. Формирование люминесцентных центров окраски при воздействии эксимерным KrF-лазером $(\lambda=248 \mathrm{~nm})$ описано в работе [21]. Результаты исследования центров окраски и люминесцентных центров в барий-фосфатных и цинк-фосфатных стеклах, содержащих серебро и медь, было проведено в работах [22-23]. В то же время модификация оптических свойств стекол при комплексном рентгеновском и лазерном облучении, применительно к созданию оптической памяти, еще недостаточно изучена.

Целью настоящей работы было исследование формирования и разрушения центров окраски в силикатных стеклах при воздействии рентгеновского и УФ наносекундного лазерного излучений, а также влияния ионов 
щелочных металлов на спектроскопические свойства центров окраски.

\section{Методика экспериментов}

В работе исследовались образцы силикатных стекол системы $\mathrm{SiO}_{2}-\mathrm{Al}_{2} \mathrm{O}_{3}-\mathrm{ZnO}-\mathrm{X}_{2} \mathrm{O}-\mathrm{XF}-\mathrm{XCl}$, где $\mathrm{X}=\mathrm{Li}$, $\mathrm{Na}$ или К. Стекла были синтезированы в Университете ИТМО. Образцы представляли собой полированные пластины толщиной $1-2 \mathrm{~mm}$.

Рентгеновское облучение образцов проводилось с помощью волнового рентгенофлуоресцентного спектрометра ARL PERFORM'X 4200 XRF на длине волны $\lambda=0.6136 \AA\left(R h_{\kappa \alpha}\right)$ в течение $16 \mathrm{~min}$ при комнатной температуре. Источником рентгеновского излучения являлась трубка с родиевым анодом. Для лазерного воздействия использовалась третья гармоника $(\lambda=355 \mathrm{~nm})$ излучения наносекундного YAG : $\mathrm{Nd}^{3+}$-лазера LS-2131M (LOTIS TII). Длительность импульсов генерации была равна $9 \mathrm{~ns}$. Частота повторения импульсов составляла $10 \mathrm{~Hz}$. Плотность энергии в импульсе была равна $15 \mathrm{~mJ} / \mathrm{cm}^{2}$. Доза лазерного облучения определялась количеством воздействующих лазерных импульсов $N$ и варьировалась в пределах $N=15-3000$. Выбор длины волны лазерного воздействия обусловлен тем, что, вопервых, на данной длине волны силикатные стекла, подвергшиеся рентгеновскому облучению, имеют высокое поглощение. Во-вторых, использование сфокусированного УФ лазерного излучения дает возможность получить область воздействия диаметром менее $1 \mu \mathrm{m}$, что важно для увеличения плотности записи оптической информации. Спектры поглощения измерялись с помощью спектрофотометра Lambda 650 (Perkin Elmer). Спектры люминесценции регистрировалась с помощью спектрофлуориметра LS-50B (Perkin Elmer). Спектральные измерения проводились при комнатной температуре.

\section{Экспериментальные результаты и обсуждение}

Рентгеновское облучение приводит к формированию интенсивной окраски у исходно бесцветных стекол. На рис. 1 показаны спектры поглощения образцов стекол с щелочными металлами и фотография образца стекла, облученного рентгеновским излучением через маску. Из рисунка видно, что для стекла с $\mathrm{Li}$ (кривая 1 на рис. 1) происходит длинноволновый сдвиг края фундаментальной полосы поглощения, и в области 250-400 nm наведенное поглощение значительно (более чем в 15 раз) увеличивается по сравнению с поглощением исходного образца. Столь существенное изменение поглощения вызвано формированием в стекле центров окраски типа ловушек электронов (e-trapped center, ETC [4-13]) и Lцентров (силанолаты, имеющие структуру $\equiv \mathrm{Si}-\mathrm{O}-\mathrm{Na}$ или $\equiv \mathrm{Si}-\mathrm{O}^{-}-\mathrm{M}^{+}$, где $\mathrm{M}$ - щелочной металл [413]). Здесь и ниже символ „三“ обозначает связь атома

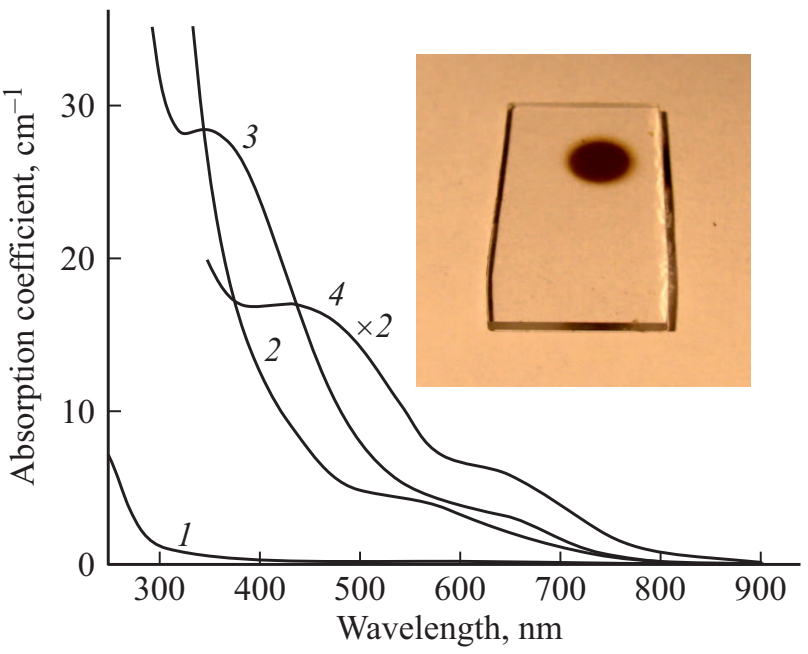

Рис. 1. Спектры поглощения стекол до (1) и после (2-4) рентгеновского облучения, стекло с $\mathrm{Li}(2), \mathrm{Na}$ (3), K (4). На вставке - фотография образца с $\mathrm{Na}$, облученного через маску.

кремния с тремя атомами кислорода. Увеличение поглощения области 400-700 nm обусловлено формированием дефектов типа немостикового кислородно-дырочного центра (non-bridging oxygen hole center, NBOH-центр, имеющий структуру $\left.\equiv \mathrm{Si}-\mathrm{O}^{\bullet}[4-13]\right)$. В последнем случае процесс образования дефекта при рентгеновском облучении может быть описан следующим уравнением [8]:

$$
\equiv \mathrm{Si}-\mathrm{O}-\mathrm{Si} \equiv+h v \rightarrow \equiv \mathrm{Si}-\mathrm{O}^{\bullet}+\bullet \mathrm{Si} \equiv,
$$

где • $\mathrm{Si} \equiv$ является Е'-центром, а символ „““ означает непарный электрон.

Рентгеновское облучение образцов стекол с $\mathrm{Na}$ также приводит к сдвигу края фундаментального поглощения в длинноволновую область на $100 \mathrm{~nm}$, и к значительному увеличению коэффициента поглощения в видимой области спектра (кривая 3 на рис. 1). Из рис. 1 также видно, что в стекле возникают две широкие полосы поглощения с максимумами на $\lambda=350$ и $650 \mathrm{~nm}$. Как и в случае стекол с Li, основной вклад в спектр поглощения вносят дефекты типа ETC, L-центров и NBOH-центров. Появление полосы поглощения в области 300-500 nm обусловлено тем, что в состав стекол с $\mathrm{Na}$ входит $\mathrm{NaCl}$, и в процессе облучения рентгеновским излучением происходит формирование междоузельных молекул хлоpa [24]. Данный процесс может быть описан следующим уравнением:

$$
\equiv \mathrm{Si}-\mathrm{Cl}+h v \rightarrow \equiv \mathrm{Si}^{\bullet}+\mathrm{Cl} .
$$

Под воздействием рентгеновского излучения происходит разрушение связи $\equiv \mathrm{Si}-\mathrm{Cl}$, и атомы хлора начинают диффундировать в стекле с образованием молекулы $\mathrm{Cl}_{2}$ [13] Данное предположение подтверждается спектрами люминесценции облученного образца (см. ниже). 

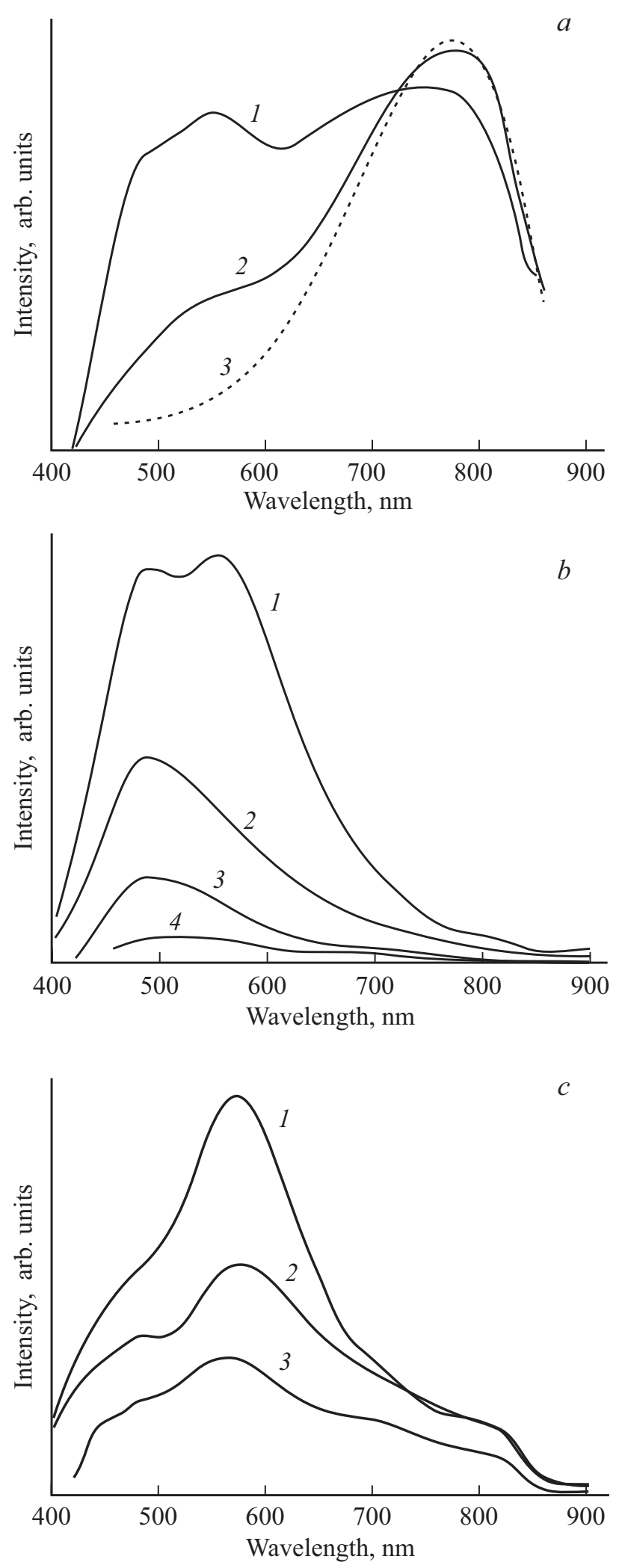

Pис. 2. Спектры люминесценции стекол с $\mathrm{Li}(a), \mathrm{Na}(b)$ и К $(c)$ после рентгеновского облучения. Длины волн возбуждения $(a)$ : 350 (1), 390 (2), 425 (3); (b): 350 (1), 390 (2), 405 (3), $425 \mathrm{~nm} \mathrm{(4);(c):} 350$ (1), 370 (2), $405 \mathrm{~nm} \mathrm{(3).}$
Относительное уменьшение коэффициента поглощения после 200 лазерных импульсов

\begin{tabular}{c|c|c|c}
\hline Длина волны, $\mathrm{nm}$ & Стекло с Li & Стекло с Na & Стекло с K \\
\hline 350 & 5.7 & 3.95 & 3.8 \\
440 & 3.8 & 3.6 & 3.64 \\
620 & 3.8 & 3.7 & 3.34
\end{tabular}

Аналогичные результаты были получены и для стекла с К (кривая 4 на рис. 1). Как видно из рисунка, в результате рентгеновского облучения в структуре стекла происходит образование L-центров и NBOH-центров, о чем свидетельствуют полосы поглощения с максимумами 450 и $640 \mathrm{~nm}$. В спектре поглощения можно выделить также полосу с максимумом $265 \mathrm{~nm}$, которая отвечает за формирование L-центра со структурой $\equiv \mathrm{Si}-\mathrm{O}^{\bullet}-\mathrm{K}$. Термообработка облученных стекол с $\mathrm{Li}$, $\mathrm{Na}$ и $\mathrm{K}$ при температуре выше $200^{\circ} \mathrm{C}$ в течение часа приводит к исчезновению наведенных полос поглощения, что свидетельствует о термическом распаде неравновесных дефектов.

Спектры люминесценции стекол после рентгеновского облучения показаны на рис. 2. Необходимо отметить, что, так как полосы поглощения и полосы люминесценции частично перекрываются, форма полос люминесценции искажена в коротковолновой их части. Для стекла с Li при возбуждении длиной волны $350 \mathrm{~nm}$ наблюдаются две широкие полосы люминесценции в области 400-600 и 620-800 nm (рис. 2,a). Первая полоса является результатом наложения двух полос люминесценции образовавшихся центров: L-центров с ионами $\mathrm{Li}$ (максимум на $\lambda=490 \mathrm{~nm}$ ) и $\mathrm{NBOH-центров}$ (максимум на $\lambda=590 \mathrm{~nm}$ ). Полоса люминесценции в области $620-800 \mathrm{~nm}$ не идентифицирована, поскольку литературные данные о люминесценции дефектов стекла в этой области спектра отсутствуют. Можно предположить, что данная полоса соответствует новому типу дефекта с участием фтора.

В стеклах с Na наблюдаются две выраженные полосы люминесценции с максимумами на $\lambda=460$ и $550 \mathrm{~nm}$ (рис. 2,b). Согласно [25], эти полосы связаны с присутствием в стекле дефектов вида $\equiv \mathrm{Si}-\mathrm{O}-\mathrm{Na}$ (первая полоса) и $\mathrm{NBOH-центров} \mathrm{(вторая} \mathrm{полоса).} \mathrm{Согласно}$ литературным данным $[13,24]$, полоса люминесценции в области $800-1000 \mathrm{~nm}$ принадлежит междоузельным молекулам хлора.

В стеклах с К после рентгеновского облучения, при возбуждении длиной волны $350 \mathrm{~nm}$ наблюдается полоса люминесценции с максимумом на $\lambda=580 \mathrm{~nm}$, соответствующая NBOH-центрам. В спектре также можно выделить две дополнительные полосы люминесценции в области $400-500$ и $700-800 \mathrm{~nm}$. Первая полоса с максимумом на $485 \mathrm{~nm}$ отвечает за люминесценцию Lцентров с ионами $\mathrm{K}^{+}$. Наличие второй полосы люминесценции $(\lambda=700-800 \mathrm{~nm})$ совпадает с результатом 


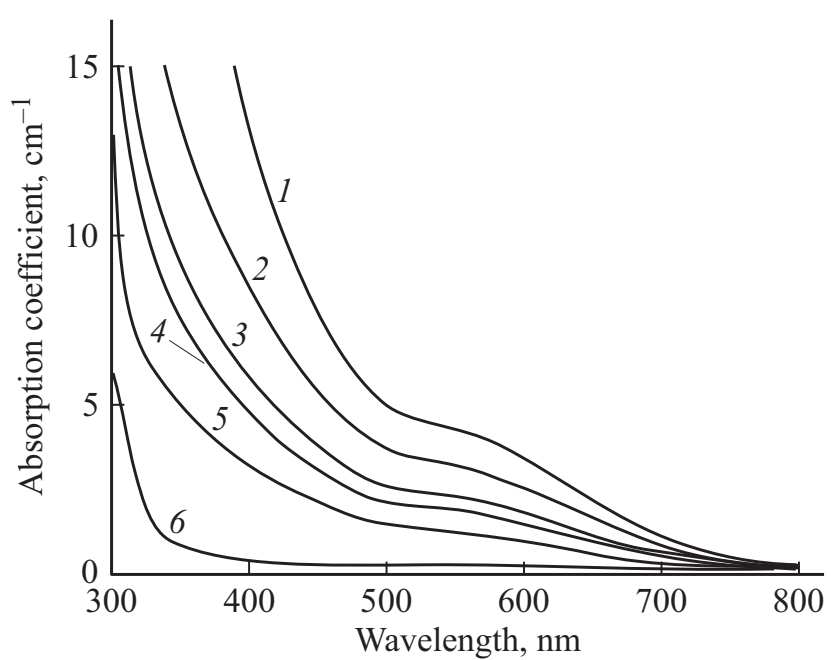

Рис. 3. Влияние дозы УФ лазерного облучения на спектры поглощения стекла с $\mathrm{Li}$, облученного рентгеновским излучением. 1 - до лазерного облучения, после 15 (2), 50 (3), 100 (4), 200 (5) лазерных импульсов, 6 - до рентгеновского облучения.

для стекла c $\mathrm{Li}$, что свидетельствует об одной и той же природе данной полосы. Однако, в отличие от стекла c Li, в стекле с К при увеличении возбуждающей длины волны наблюдается уменьшение интенсивности люминесценции в области $700-800 \mathrm{~nm}$ лишь при возбуждении излучением с $\lambda=405 \mathrm{~nm}$. Такая особенность может быть объяснена различным окружением сформированных центров окраски или же строением самих центров (замена ионов $\mathrm{Li}+$ на $\mathrm{K}+$ ).

На рис. 3 показаны спектры поглощения стекла c $\mathrm{Li}$, облученного рентгеновским излучением, после воздействия УФ лазерного излучения. Из рисунка видно, что под действием лазерного облучения происходит частичное обесцвечивание стекла в облученной зоне. Уже после воздействия 15 лазерных импульсов наблюдаются сдвиг края спектра поглощения в коротковолновую область и уменьшение коэффициента поглощения в области $300-700 \mathrm{~nm}$. Дальнейшее увеличение дозы лазерного воздействия приводит к усилению данного эффекта. Причем наиболее сильное уменьшение поглощения происходит в УФ области спектра. Кроме уменьшения поглощения в облученных лазером зонах наблюдается также уменьшение и исчезновение люминесценции. Аналогичные спектры поглощения были получены для стекол с $\mathrm{Na}$ и K. Как и в случае стекла c Li, увеличение дозы лазерного облучения приводит к уменьшению поглощения стекол в УФ и видимой областях спектра.

На рис. 4 показано сравнение изменения коэффициента поглощения стекол с $\mathrm{Li}$, $\mathrm{Na}$ и $\mathrm{K}$ в зависимости от величины дозы лазерного облучения для различных длин волн. Как видно из рисунка, наиболее сильное просветление наблюдается для стекла с Li и происходит при $N<50$. Величины ослабления коэффициента погло-
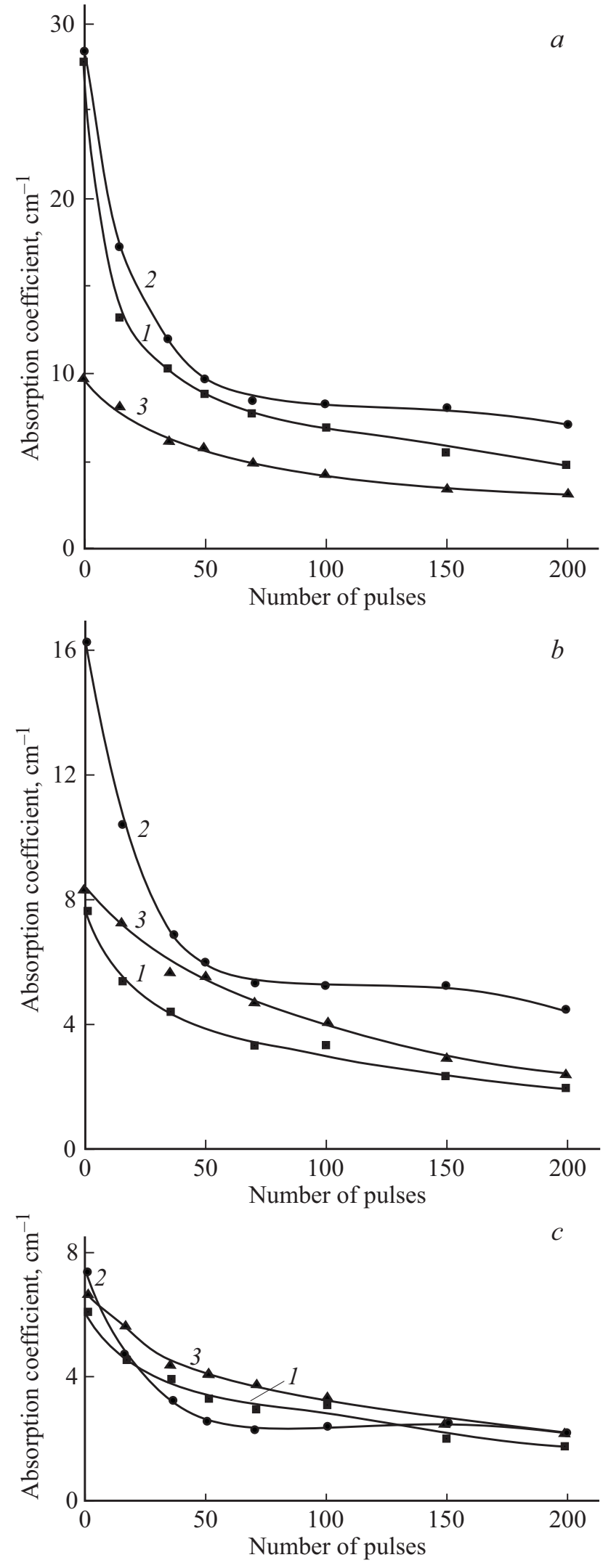

Рис. 4. Зависимость коэффициента поглощения на длине волны $350 \mathrm{~nm}(a), 440 \mathrm{~nm}(b)$ и $620 \mathrm{~nm}(c)$ от дозы лазерного облучения (количества лазерных импульсов). Стекло с $\mathrm{Li}$ (1), $\mathrm{Na}(2), \mathrm{K}(3)$. 


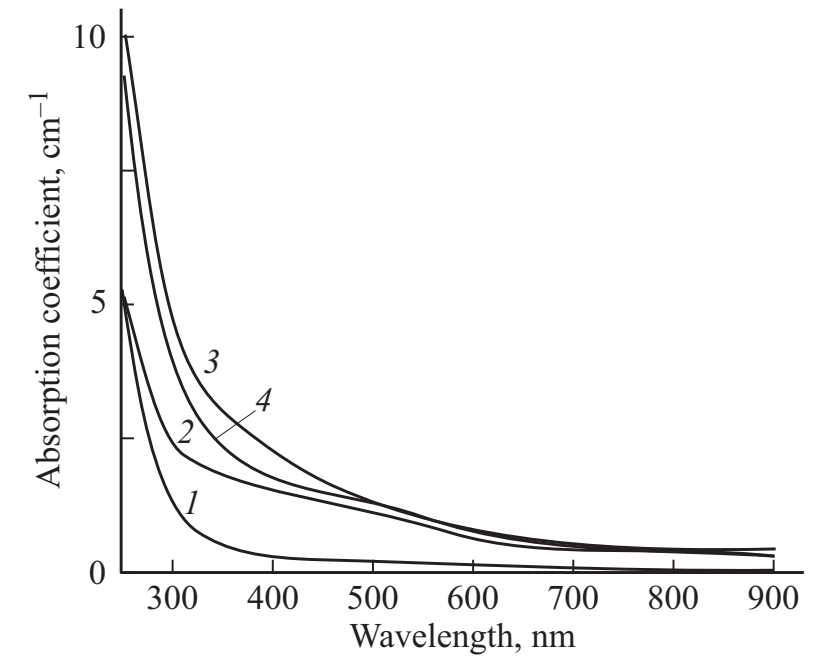

Рис. 5. Спектры поглощения образцов, не подвергнутых рентгеновскому облучению, до (1) лазерного облучения и после (2-4) облучения 3000 УФ лазерными импульсами, стекло с Li (2), $\mathrm{Na}(3), \mathrm{K}(4)$.

щения после воздействия 200 импульсов УФ наносекундного лазерного излучения представлены в таблице. Из таблицы и рис. 4 следует, что относительное уменьшение коэффициента поглощения, возникающее после лазерного облучения, лежит в пределах 3.3-5.7 для различных длин волн. Этого контраста достаточно для уверенного считывания оптической информации. Наибольший контраст наблюдается в УФ области спектра. Так как запись и считывание оптической информации в данном случае происходит УФ лазерным излучением, то плотность записи информации может быть лучше, чем $1 \mathrm{bit} / \mu \mathrm{m}$. Так как при лазерном воздействии происходит тушение люминесценции в облученной зоне, то считывание информации может производиться и по изменению интенсивности люминесценции.

Для сравнения были проведены контрольные эксперименты, в которых образцы стекол, не подвергнутых рентгеновскому облучению, облучались УФ лазерным излучением. Эксперименты показали, что в данном случае также происходит формирование центров окраски. Однако данный эффект проявляется значительно слабее, чем в случае рентгеновского облучения: заметное изменение поглощения в образцах возникает после воздействия более 1000 лазерных импульсов. На рис. 5 показаны спектры поглощения образцов, не подвергнутых рентгеновскому облучению, после УФ лазерного облучения с $N=3000$ импульсов. Из рисунка видно, что наиболее сильное увеличение поглощения происходит в УФ области спектра $\lambda=250-350 \mathrm{~nm}$, что указывает на образование в стекле ЕTC и L-центров. В видимой области спектра коэффициент поглощения увеличивается незначительно. Можно предположить, что в случае УФ лазерного облучения образование структурных дефектов сопровождается их термическим разрушением, что снижает скорость накопления в стекле центров окраски. В отличие от случая рентгеновского облучения после лазерного воздействия наиболее сильное увеличение поглощения в УФ области спектра наблюдается для стекла с Na. Таким образом, с точки зрения записи оптической информации УФ лазерное воздействие на стекла после рентгеновского облучения является более эффективным методом, чем только лазерное облучение, так как при этом создается более высокий контраст при значительно меньшей дозе лазерного облучения.

Разрушение дефектов стекла при УФ лазерном облучении после рентгеновского облучения, сопровождающееся просветлением образцов, вызвано двумя основными процессами. Во-первых, на длине волны $\lambda=355 \mathrm{~nm}$ излучения УФ лазера облученные рентгеном образцы имеют высокое поглощение (рис. 1). Поэтому в процессе облучения УФ лазером происходит локальный нагрев области воздействия, приводящий к термическому разрушению дефектов. Во-вторых, интенсивное лазерное УФ излучение вызывает фотоионизацию матрицы стекла, что, в свою очередь, способствует разрушению сформированных структурных дефектов и образованию новых. Свободные электроны, возникающие при фотоионизации, захватываются E'- и L-центрами, что приводит к их перестройке и уменьшению поглощения в УФ области спектра. Уменьшение поглощения в видимой области спектра при УФ лазерном воздействии связано с уменьшением концентрации NBOH-центров. Данный процесс можно описать следующими выражениями:

$$
\begin{gathered}
\equiv \mathrm{Si}-\mathrm{O}^{\bullet}+e \rightarrow \equiv \mathrm{Si}-\mathrm{O}, \\
2(\equiv \mathrm{Si}-\mathrm{O}) \rightarrow \equiv \mathrm{Si}-\mathrm{O}-\mathrm{O}-\mathrm{Si} \equiv,
\end{gathered}
$$

т. е. NBOH-центр захватывает свободный электрон, образовавшийся в процессе фотоионизации, и возникает NBO-центр. Вследствие локального нагрева ускоряется диффузия в стекле, и происходит компенсация двух NBO-центров с восстановлением структуры сетки стекла.

Необходимо подчеркнуть, что при УФ лазерном воздействии на стекла, подвергшиеся рентгеновскому облучению, одновременно происходят два конкурирующих процесса. Во-первых, образование новых неравновесных структурных дефектов (рис. 5). Во-вторых, разрушение неравновесных структурных дефектов, возникших в результате рентгеновского облучения. Как показали наши эксперименты, второй процесс в данном случае преобладает.

\section{Выводы}

Экспериментально показано, что под действием рентгеновского излучения в стеклах возникают центры окраски, обладающие люминесцентными свойствами, что связано с увеличением концентрации структурных дефектов сетки стекла. Под действием УФ лазерного излучения происходит разрушение этих дефектов, 
что сопровождается частичным обесцвечиванием стекла и исчезновением люминесценции в облученных зонах. Наибольший контраст изменения поглощения, равный 5.7, наблюдается в УФ области спектра в стеклах, содержащих ионы лития. При использовании данных эффектов для записи оптической информации плотность записи может быть лучше, чем $1 \mathrm{bit} / \mu \mathrm{m}$, так как запись и считывание могут производиться УФ лазерным излучением.

\section{Финансирование работы}

Работа выполнена при финансовой поддержке Министерства образования и науки Российской Федерации (Проект 16.1651.2017/4.6).

\section{Конфликт интересов}

Авторы заявляют, что у них нет конфликта интересов.

\section{Список литературы}

[1] Schreurs J.W. // J. Chem. Phys. 1967. V. 47. P. 818.

[2] Sheng J., Kadono K., Yazawa T. // Phys. and Chem. of Glasses-Europ. J. Glass Sci. and Technol. B. 2002. V. 43. P. 2594.

[3] Sheng J., Kadono K., Yazawa T. // Appl. Radiation and Isotopes. 2002. V. 56. P. 621.

[4] Mackey J.H., Smith H.L., Halperin A. // J. Phys. Chem. Solids. 1966. V. 27. P. 1759.

[5] Wua Y.J., Yang X., Zhang J. // Intern. J. Hydrogen Energ. 2009. V. 34. P. 1123.

[6] Suszynska M., Macalik B. // Nucl. Instr. and Meth. in Phys. Res. B. 2001. V. 179. P. 383.

[7] Skuja L. // J. Non-Cryst. Sol. 1998. V. 239. P. 16.

[8] Tsai H.-S., Chao D.-S., Wu Y.-H., He Y.-T., Chueh Y.-L., Liang J.H. // J. Nucl. Mater. 2014. V. 453. P. 233.

[9] Xinjie F., Lixin S., Jiacheng L. // J. Rare Earths. 2014. V. 32. P. 1037.

[10] Natura U., Ehrtl D. // Glastech. Ber. Glass Sci. Technol. 2001. V. 74. P. 23

[11] Dmitryuk A.V., Paramzina S.E., Perminov A.S., Solov'eva N.D., Timofeev N.T. // J. Non-Cryst. Sol. 1996. V. 201. P. 173.

[12] Zatsepin A.F., Guseva V.B., Zatsepin D.A. // Glass Phys. and Chem. 2008. V. 34. N 6. P. 709.

[13] Vaccaro L., Cannas M., Radzig V., Boscaino R. // Phys. Rev. B. 2008. V. 78. ID 075421.

[14] Rodriguez J.A., Vasquez-Agustin M., Morales-Sanchez A., Aceves-Mijare M. // J. Nanomater. 2014. V. 2014. ID 409482.

[15] Sheng J., Kadono K., Yazawa T. // Appl. Radiation and Isotopes. 2002. V. 56. P. 621.

[16] Hirao K., Qio J., Shimizugawa Y. // Jpn. J. Appl. Phys. 1998. V. 37. P. 2259.

[17] Poirier G., Nalin M., Cescato L, Messaddeq Y., Ribeiro S. // J. Chem. Phys. 2006. V. 125. ID 161101.

[18] Dubrovin V.D., Ignatiev A.I., Nikonorov N.V., Sidorov A.I., Shakhverdov T.A., Agafonova D.S. // Opt. Mater. 2014. V. 36. P. 753.
[19] Klyukin D.A., Sidorov A.I., Ignatiev A.I., Nikonorov N.V. // Opt. Mater. 2014. V. 38. P. 233.

[20] Royon A., Bourhis K., Bellec M., Papon G., Bousquet B., Deshayes Y., Cardinal Th., Canioni L. // Adv. Mater. 2010. V. 22. P. 5282.

[21] Игнатьев А.И., Игнатьев Д.А., Никоноров Н.В., Сидоров А.И. // Опт. и спектр. 2015. Т. 119. № 2. С. 249.

[22] Murashov A.A., Sidorov A.I., Stolyarchuk M.V., Boiko M.E. // J. Non-Cryst. Sol. 2017. V. 477. P. 1-6.

[23] Murashov A.A., Sidorov A.I., Shakhverdov T.A., Stolyarchuk M.V. // Opt. Eng. 2017. V. 56. ID 117106.

[24] Karna S.P., Kurtz H.A., Shedd W.M., Pugh R.D., Singaraju B. // IEEE Transact. Nucl. Sci. 1999. V. 46. P. 1544.

[25] Defects in $\mathrm{SiO}_{2}$ and Related Dielectrics: Science and Technology. (NATO Science Series II. V. 2) / Ed. by Pacchioni G., Skuja L., Griscom D.L. Dordrecht: Kluwer, 2000. 